\title{
ESTUDO DA VIABILIDADE TÉCNICA DO PROCESSO DE GEORREMEDIAÇÃO PARA TRATAMENTO DE PERCOLADOS DE ATERROS SANITÁRIOS (CHORUME DA ETP-MURIBECA: UM ESTUDO DE CASO)
}

\author{
José Beldson Elias Ramos \\ Professor do Instituto Federal de Educação, Ciência e Tecnologia do Rio Grande do Norte; \\ e-mail: beldson.elias@ifrn.edu.br \\ Eldemar de Albuquerque Menor \\ Professor da Universidade Federal do Pernanbuco; e-mail: menor@terra.com.br
}

\section{RESUMO:}

A depuração de chorume nas ETP's (Estações de Tratamento de Percolados) de aterros sanitários, envolve volumes consideráveis e, geralmente, constatam-se deficiências de performance no seu tratamento. Os resultados das pesquisas voltadas para remediação das suas características tóxicas, que variam de aterro para aterro, vêm conduzindo a propostas em que esse poluente, seja como produto residual líquido ou como pasta adensada (lodo), é sempre descartado na Natureza. Na tese de doutorado em foco apresenta-se uma metodologia alternativa (georremediação aditivada, GAD) para melhorar substancialmente a degradação da matéria orgânica recalcitrante contida no chorume, associada a uma redução significativa nas concentrações de alguns metais pesados do efluente. No processo GAD, se emprega um blendindustrial caulínico, ativado com cal hidratada, atuandocomoagente depurador, através da preparação de uma polpa com o chorume bruto. Essa nova metodologia, que pode ser adotada em escala operacional, permite a recuperação das frações residuais sólida e líquidas após a performance depuradora. Ambas as frações podem ser industrialmente aproveitadas e/ou adequadamente descartadas. A viabilidade operacional é também sustentada por um reduzido tempo de reação (máximo de 15 minutos) e baixos custos.

PALAVRAS-CHAVES: Percolado, Tratamento, BlendCaulínico Aditivado, Georremediação

\section{VIABILITY STUDY OF LANDFILLS LEACHATE TREATMENT BY USING GEORREMEDIATION TECHNICS (A CASE STUDY OF MURIBECA'S LANDFILLS)}

\begin{abstract}
The clearance of manure in ETP's (Wastewater Treatment Percolates) from landfills involves considerable volumes and usually deficiencies are found in the performance of their treatment. The results of research aimed at remediation of their toxic characteristics, ranging from landfill to landfill, are leading to proposals that that pollution, either as a waste liquid or paste as dense (sludge), it is always discarded in nature. In the doctoral thesis in focus presents an alternative methodology (georremediação activated, GAD) to substantially improve the degradation of recalcitrant organic matter contained in manure, associated with a significant reduction in the concentrations of some heavy metals from wastewater. GAD in the process, it employs a blend industrial clays, whether or activated with hydrated lime, acting as a debugger, by preparing a pulp with the raw leachate. This
\end{abstract}


new methodology, which can be adopted in operational scale, allows the recovery of fractions solid and liquid waste after the purifying performance. Both fractions can be industrially exploited and / or properly discarded. The operational viability is also supported by a reduced reaction time (maximum 15 minutes) and low costs.

KEYWORDS:Leachate, Treatment, Blend KaolinicActived, Georremediación 


\section{ESTUDO DA VIABILIDADE TÉCNICA DO PROCESSO DE GEORREMEDIAÇÃO PARA TRATAMENTO DE PERCOLADOS DE ATERROS SANITÁRIOS (CHORUME DA ETP-MURIBECA: UM ESTUDO DE CASO)}

\section{INTRODUÇÃO}

A depuração de chorume em Estações de Tratamento de Percolados (ETP's) envolve volumes consideráveis e, geralmente, são constatadas deficiências de performance em seu tratamento. Os resultados das pesquisas voltadas para remediação das características tóxicas desses efluentes, que variam de aterro para aterro, vêm conduzindo a propostas em que, tanto o produto residual líquido (chorume tratado), quanto à pasta adensada de resíduos (lodo), terminam sempre indesejavelmente descartados na Natureza.

Esta tese enfoca o estudo de viabilidade técnica de uma nova rota de processo, inovadora para tratamento de percolados de aterros sanitários de resíduos sólidos urbanos (RSU), visando, sobretudo, altas performances na degradação da matéria orgânica (MO). O escopo da investigação pretendeu, em primeira instância, reduções nos níveis de DBO, DQO e, eventualmente, de algumas espécies químicas metálicas, em escala operacional e prazo reduzido, com a condicionante de custos assimiláveis em impostos públicos.

O desenvolvimento dessa técnica alternativa teve como meta melhores desempenhos na qualidade de efluentes tratados por processos de degradação biológica da MO, utilizando-se, como caso-estudo, efluentes procedentes da estação de tratamento de percolados (ETP), do Aterro Controlado da Muribeca (ACM), localizado na Região Metropolitana do Recife (RMR), Pernambuco - Brasil.

Do ponto de vista estritamente técnico, o processo desenvolvido apresenta boas performances de eficiência, sobretudo no que concerne a redução da carga orgânica recalcitrante do percolado em estudo. Levando-se em consideração a qualidade do tratamento obtido nos experimentos, bem como o tempo de processamento, a metodologia proposta apresenta-se como viável e competitiva, indiscutivelmente atribuída ao benefício ambiental resultante da aplicação dessa tecnologia.

\section{ATERRO CONTROLADO DA MURIBECA}

O Aterro Controlado da Muribeca (ACM) situa-se no município de Jaboatão dos Guararapes, Pernambuco, próximo ao eixo da integração Prazeres - Jaboatão, distando 16 Km do centro do Recife. Essa unidade sanitária recebeuno período (2007-2008) cerca de 3.000 ton/dia de Resíduos Sólidos Urbanos (RSU) das cidades do Recife e Jaboatão dos Guararapes, a uma taxa aproximada de 1.000 .000 ton/ano, sendo a composição gravimétrica dos resíduos constituída de $60 \%$ de material orgânico, 15\% de papéis, $8 \%$ de plásticos, $2 \%$ de metais, $2 \%$ de vidros e $13 \%$ de outros materiais (Lins, 2003).

O ACM é a maior unidade desse tipo em operação no Estado de Pernambuco, ocupando uma área de 60 ha na bacia hidrográfica do rio Jaboatão, onde nasce um córrego (sem nome) que vai desaguar no rio Muribequinha, afluente da sua margem direita. A área de disposição situa-se entre as seguintes coordenadas UTM: 280.000 e 282.000 Leste e 9.096.000 e 9.098.000 Norte (Lins, 2003). Na realidade, essa região vem sendo degrada desde 1986, quando funcionava como depósito de lixo a céu aberto. Segundo Lins (op. cit), 
“após um amplo diagnóstico do meio físico (1994), foi iniciado um processo de tratamento dos resíduos e recuperação ambiental, visando à transformação do lixão em aterro controlado (situação atual) e, posteriormente, em aterro sanitário. Nesse processo, foram construídas 9 células (200x200m), que alcançam na atualidade alturas entre 20 a40 metros". Esse projeto ainda está em andamento, e contempla a ampliação da ETPMuribeca, que já apresenta vários problemas operacionais com o processo biológico de tratamento adotado.

\section{ESTAÇÃO DE TRATAMENTO DE PERCOLADOS (ETP-MURIBECA)}

A ETP-Muribeca foi implantada em 2002, adotando um tratamento misto para o percolado do ACM, com base em dois subsistemas distintos: lagoas de estabilização (Figuras 1 e 2), e barreira reativa associada à fitorremediação.

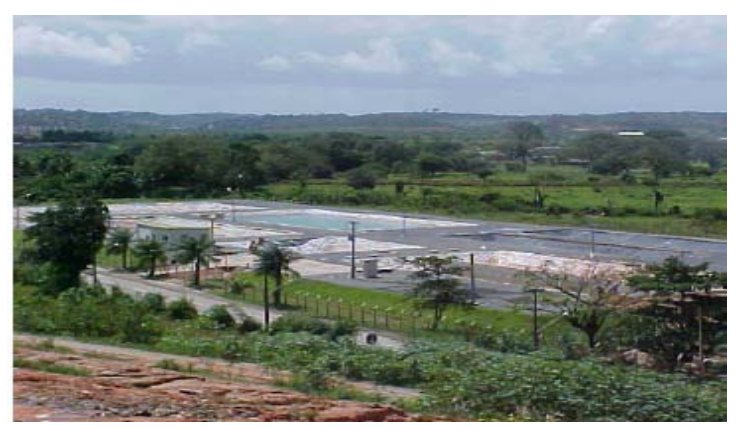

Figura 1 - Vista panorâmica

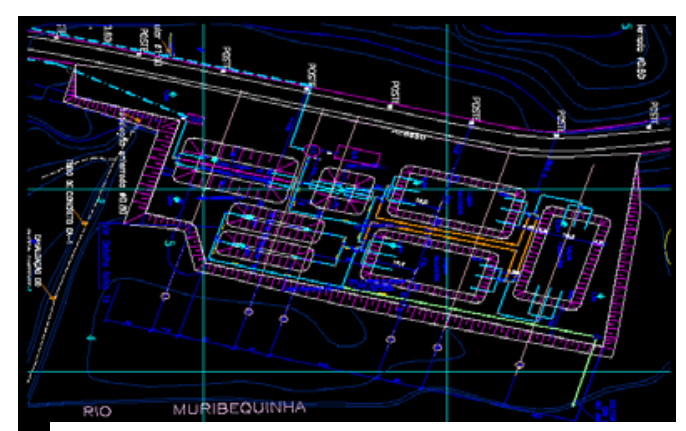

Figura 2 - Esquema da ETPMuribeca

A seqüência de lagoas é disposta em série: caixa de areia, duas lagoas de decantação, uma lagoa anaeróbia e três lagoas facultativas, além de um sistema bioquímico que utiliza o conjunto solo-plantas-barreira reativa e microrganismos para remoção e degradação de contaminantes (fitorremediação). Por fim, o percolado dito "tratado" é lançado no rio Muribequinha (Classe 3), afluente do rio Jaboatão. O sistema de lagoas de estabilização constitui um processo biológico de tratamento caracterizado pela simplicidade e baixo custo, ondea estabilização da MO é realizada pela oxidação bacteriológica (oxidação aeróbia e/ou fermentação anaeróbia) e/ou redução fotossintética das algas, em simbiose, sob influência de condições climáticas como o vento, temperatura, chuvas e luz solar. Jucá et al.(1999) assinalam que este sistema é adequado para as condições do nordeste brasileiro, em função do clima tropical (temperatura e insolação elevadas), operação simples, e necessidade de pouco ou nenhum equipamento.

\section{CARACTERÍSTICAS FÍSICAS E OPERACIONAIS DA ETP- MURIBECA}

O atual fluxograma para tratamento do chorume do ACM (Lins et al., 2006) pode ser resumido através das seguintes fases:

-Recirculação de chorume (pré-tratamento): dimensionada para uma vazão de $\mathrm{Q}_{\mathrm{R}}=3,5 \mathrm{l} / \mathrm{seg}$ (70\% da vazão média anual gerada nas células), com dois objetivos principais: (a) reduzir a vazão e carga orgânica a tratar, através da reinjeção do percolado gerado na massa de lixo já confinada; e (b) reduzir a carga de sólidos em suspensão; 
-Tratamento secundário: através de uma seqüência de lagoas de estabilização, dimensionadas para tratar $\mathrm{Q}_{\mathrm{afl}}=1,5 \mathrm{l} / \mathrm{seg}$ (30\% da vazão média anual de projeto), objetivando uma eficiência de remoção dos poluentes compatível com as exigências e normas do órgão ambiental estadual (CPRH - Companhia Pernambucana de Recursos Hídricos);

- Tratamento terciário:onde se incorporou uma unidade piloto de investigação para verificar a eficiência do polimento do efluente, através do sistema bioquímico (SBQ) associado à fitorremediação. Essa unidade experimental foi dimensionada para tratar uma vazão de $\mathrm{Q}_{\mathrm{SBQ}}=0,5 \mathrm{l} / \mathrm{seg}$, e recebeu uma camada vegetal no leito, na qual foram plantadas espécies nativas de várzea: typhadomingensis, a popular "taboa".

O sistema operacional atualmente em vigência na ETP-Muribeca tem as seguintes características (Tabela 1):

Tabela 1 - Características operacionais projetadas para a ETP-Muribeca

\begin{tabular}{|l|l|}
\hline Capacidade total de acumulação & $14.083 \mathrm{~m}^{3}$ \\
\hline Vazão afluente média de chorume & $5,0 \mathrm{~L} / \mathrm{seg}$ \\
\hline Area total da E. T. P. & $21.146 \mathrm{~m}^{2}$ \\
\hline Capacidade de tratamento & $129.600 \mathrm{~L} /$ dia \\
\hline Capacidade da lagoa de recirculação & $10.310 \mathrm{~m}^{3}$ \\
\hline
\end{tabular}

\section{Fonte: Secretaria de Serviços Públicos, 2006}

A ETP-Muribeca considera os padrões de contaminação constatados durante um monitoramento de mais de dois anos de amostragem mensal simples (Tabela 2).

Tabela 2 - Variação dos teores de substâncias contaminantes Dissolvidas no percolado do ACM (Lins et al., 2006)

\begin{tabular}{|c|c|}
\hline PARÂMETRO & FAIXA DE VARIAÇÃO (mg/L) \\
\hline $\mathrm{K}^{+}$ & $530-2200$ \\
\hline $\mathrm{Na}^{+}$ & $380-1700$ \\
\hline $\mathrm{Ca}^{+2}$ & $130-740$ \\
\hline $\mathrm{Mg}^{+2}$ & $20-320$ \\
\hline $\mathrm{Cl}^{-}$ & $760-3400$ \\
\hline $\mathrm{SO}_{4}^{-2}$ & $100-5400$ \\
\hline $\mathrm{Mn}$ & $0,15-2,50$ \\
\hline $\mathrm{Cd}$ & $0,05-0,20$ \\
\hline Co & $0,40-1,40$ \\
\hline $\mathrm{Cr}$ & $0,07-0,70$ \\
\hline $\mathrm{Fe}$ & $1,00-70,00$ \\
\hline $\mathrm{Cu}$ & $0,20-1,30$ \\
\hline $\mathrm{Zn}$ & $0,15-0,60$ \\
\hline $\mathrm{Ni}$ & $0,05-0,40$ \\
\hline $\mathrm{Pb}$ & $0,20-5,00$ \\
\hline $\mathrm{NO}_{3}^{-}$ & $0,90-729$ \\
\hline $\mathrm{NH}_{4}^{+}$ & $0,40-1100$ \\
\hline Demanda Bioquímica de Oxigênio & $130-7500$ \\
\hline Demanda Química de Oxigênio & $1560-12600$ \\
\hline Sólidos Totais & $5200-13000$ \\
\hline $\mathrm{pH}$ & $6,5-8,8$ \\
\hline Cor (UH) & $1050-5000$ \\
\hline
\end{tabular}




\section{MATERIAIS E MÉTODOS}

\section{Procedimentos de coleta e preservação das amostras do percolado}

O objetivo primordial da pesquisa era o de melhorar radicalmente o processo da degradação da MO contida no poluente e, na medida do possível, provocar uma redução drástica nos teores dos metais pesados (MP). A hipótese de trabalho considerou como ponto de partida o estudo mineralógico e afinidades geoquímicas do lodo e, posteriormente, a amostragem do percolado da ETP-Muribeca nas condições de entrada (input, $G A D$ ) e na condição final (output, $G$ ). A coleta do lodo (draga de Pertensen) foi feita nas lagoas LD, LA e LF1, sendo realizada a dragagem de 3 (três) alíquotas de sedimento em cada lagoa (pontos distintos) e, após quarteamento, este material foi destinado à secagem em CNTP (sombra).

Foram realizadas quatro amostragens de percolado no sistema de lagoas do fluxograma: duas deoutput (abril e novembro/2005) e duas de input (abril e setembro/2006). O chorume foi acondicionado em recipientes de poliestireno, previamente lavados com água destilada e, na ocasião da amostragem, relavados com o próprio chorume a ser coletado. Cada coleta, de 100L, foi imediatamente conduzida ao laboratório, nos recipientes hermeticamente fechados, e armazenada em CNTP, em lugar seco e escuro. Todos os testes e processos analíticos foram realizados no prazo de 40 dias após a data da coleta.

\section{Caracterização do blendcaulínico depurante}

A matéria-prima utilizada no processo de georremediação (GAD), corresponde a um blendcaulínico industrial ( $\mathrm{CC}=\mathrm{B} 3 \mathrm{~A}$, referência industrial), na forma de "espaguete". A análise química do blendcaulínico permitiu determinar que esse produto, estequiometricamente, é composto por: $90 \%$ de caulinita (com traços de muscovita), $4 \%$ de fração residual de minerais pesados (ilmenita, goethita e apatita), $4 \%$ de MO e $2 \%$ de quartzo.

\section{Caracterização do Aditivo de Cal Depurante}

$\mathrm{O}$ aditivo utilizado no processo GAD foi uma cal hidratada magnesiana, tipo CH-III, com a finalidade de remover a cor (reduzindo conseqüentemente a turbidez) e MP do chorume. A cal hidratada resulta de um processamento industrial a partir da calcinação de rochas carbonáticas, a temperaturas entre 850 a $1200{ }^{\circ} \mathrm{C}$ (Pezente, 2007).

\section{Procedimentos Laboratoriais: Processo de Georremediação Aditivada (GAD)}

$\mathrm{Na}$ preparação das polpas foram utilizadas proporções de 100, 200 e $400 \mathrm{~g}$ de blendcaulínico CC (com aditivo = GAD), para cada litro de chorume. Indiferentemente das relações custos/benefícios, as proporções testadas tiveram como objetivo verificar as performances do tratamento em função de quantidades variáveis do blend, a fim de se visualizar a quantidade ótima dessa fração sólida no processo.

O tempo padrão de preparação da polpa foi fixado em 10-15 minutos a $800 \mathrm{rpm}$, em mixereletrônico, conforme avaliações empíricas acerca do "ótimo" operacional para esse procedimento. Ato contínuo, cada polpa processada várias vezes (mesma amostra) foi submetida à passagem em filtro a vácuo, dotado com papel de filtro 90 (poro máximo = $22,4 \mu \mathrm{m}$; poro médio $=13,2 \mu \mathrm{m}$ ), recuperando-se, separadamente, também em duplicatas, as frações sólidas (retidas no filtro, e aqui denominadas LMIX-100, LMIX-200 e LMIX-400) e as correspondentes frações líquidas residuais (FRL's), conforme mostra a Tabela 3. 
Tabela 3 - Preparação das amostras para análises laboratoriais (GAD)

\begin{tabular}{|c|c|c|c|c|}
\hline Amostras & Aditivo (\%) & Blend & FRL & LMIX \\
\hline$(0)$ & - & - & - & - \\
\hline$(1)$ & 10 & CC (90-10) & FRL-200(90-10) & LMIX-200(90-10) \\
\hline $\mathbf{( 2 )}$ & $\mathbf{2 5}$ & CC (75-25) & FRL-200(75-25) & LMIX-200(75-25) \\
\hline$(3)$ & $\mathrm{R}^{*}(25)$ & CC (75-25) & FRL-400(75-25) & LMIX-400(75-25) \\
\hline
\end{tabular}

As alíquotas dos LMIX's foram desidratadas em estufa, sob temperatura de $60^{\circ} \mathrm{C}$, no prazo de 96 horas. O material desidratado foi pulverizado, em cadinho de porcelana, $100 \%$ passante na malha de 100 mesh, para análises em laboratório. Alíquotas de $10 \mathrm{~g}$ desse LMIX foram destinadas ao ACTLABS (ActivationLaboratories, Ontário, Canadá) para determinação dos óxidos fundamentais e mais 40 elementos traços. Outras alíquotas (1g) foram destinadas ao Laboratório de Materiais Avançados (LMA/Dep. de Física/UFPE), para análises DRX, visando-se a identificação qualitativa das principais frações minerais, antes e após o processamento com chorume. Finalmente, alíquotas de 150mg foram expedidas para Central Analítica (CA/Dep. de Química Fundamental/UFPE) para análises $\mathrm{C}-\mathrm{N}-\mathrm{H}-\mathrm{S}$, realizadas por cromatografia gasosa em um Analisador Elementar Carlo Erba, modelo EA-1110.Dois litros de cada FRL (quantidade resultante do processamento de 3L de percolado bruto), assim como dos percolados in natura tanto do input como do output, foram enviados para análises físico-químicas no LAMSA - Laboratório de Análises Minerais, Solos e Água da UFPE. Essas análises (DBO, DQO, pH, cor, turbidez, alcalinidade, dureza, sólidos e MP) foram realizadas conforme procedimentos recomendados pelo "21th Standard Methods for theExaminationofWaterandWastewater (2005)”.

\section{RESULTADOS EXPERIMENTAIS E DISCUSSÃO}

As pesquisas foram conduzidas tomando-se como opção a preparação de polpas com concentrações sólido-líquido de $200 \mathrm{~g}$ de blendcaulínico aditivado / L de percolado, com intuito de aproveitar a fração residual sólida do processo GAD. O ponto de partida para escolha da quantidade do aditivo foi os estudos de Picchiet al., (1988), que apontaram um teor de $10 \%$ de cal hidratada como "ótimo" economicamente viável para confecção de tijolos prensados solo-cimento.A escolha do aditivo $\mathrm{Ca}(\mathrm{OH})_{2}$ baseou-se nas indicações de Cincotto (1977), Picchiet al. (1988), e Alves et al. (2006), que apontaram propriedades de forte poder de coagulação para esse composto e, inclusive, altas performances nas reduções de turbidez e de MP de percolados. De fato, Alves et al. (op cit.) comprovaram que a utilização de hidróxido de cálcio, associado à bentonita, pode remover de 70 a $90 \%$ da cor e turbidez de chorumes. Na realidade, a cal hidratada não atuaria apenas como coadjuvante, mas funcionaria como coagulante capaz de "quebrar" radicalmente estruturas orgânicas complexas (por exemplo: as substâncias húmicas) em curto espaço de tempo (10-15 min) e, inclusive, provocar a adsorção de espécies metálicas no caulim.Os resultados analíticos produzidos sobre o chorume bruto (input), coletado no período de estiagem (concentrado e em condição anaeróbia extrema), tratado pelo processo GAD confirmaram, efetivamente, que a incorporação de $\mathrm{Ca}(\mathrm{OH})_{2}$ possibilitou o aumento de eficiência na eliminação de MO, dramática remoção de amônia e de óleos e graxas, resultando em flagrante melhoria na qualidade de efluente tratado (Tabela 4). Tomando-se 
como referência a "amostra 2", constata-se que a DBO foi reduzida em 84\%, a DQO em $47 \%$, a amônia em $94,3 \%$, e os óleos e graxas em $70,4 \%$.

Tabela 4 - Caracterização química das FRL's de input com blendcaulínico aditivado

\begin{tabular}{|c|c|c|c|c|c|c|c|c|}
\hline $\begin{array}{c}\text { Amostras } \\
\text { (GAD) }\end{array}$ & $\begin{array}{c}\text { DBO } \\
\left(\mathrm{mg} \mathrm{O}_{2} / \mathrm{L}\right)\end{array}$ & $\begin{array}{c}\text { DQO } \\
\left(\mathrm{mg} \mathrm{O}_{2} / \mathrm{L}\right)\end{array}$ & pH & $\begin{array}{c}\text { Óleos e graxas } \\
\mathrm{mg} / \mathrm{L}\end{array}$ & $\begin{array}{l}\text { SDT } \\
\mathrm{mg} / \mathrm{L}\end{array}$ & $\begin{array}{l}\text { SDV } \\
\mathrm{mg} / \mathrm{L}\end{array}$ & $\begin{array}{l}\text { SDF } \\
\mathrm{mg} / \mathrm{L}\end{array}$ & $\begin{array}{c}\mathrm{N}-\mathrm{NH}_{3} \\
\mathrm{mg} / \mathrm{L}\end{array}$ \\
\hline (o) & $3.270,3$ & $3.445,5$ & 7,95 & 71,0 & $10.436,0$ & $1.690,0$ & $8.746,0$ & 958,0 \\
\hline (1) & 592,4 & $2.161,2$ & 11,66 & 51,0 & $8.163,0$ & $1.098,0$ & $7.065,0$ & 105,5 \\
\hline (2) & 509,2 & $1.801,0$ & 11,70 & 21,0 & $7.402,0$ & $1.331,0$ & $6.071,0$ & 54,1 \\
\hline (3) & 431,5 & $1.587,0$ & 12,29 & 9,0 & $7.891,0$ & 954,0 & $6.937,0$ & 6,32 \\
\hline
\end{tabular}

Fonte: DEQ/UFPE, 2007. Nota: SDT = Sólidos Dissolvidos Totais; SDV = Sólidos Dissolvidos Voláteis; SDF = Sólidos Dissolvidos Fixos; N-NH3 = Nitrogênio amoniacal. (Análises em triplicatas).

Na amostra de reprocessamento (“caso 3", Tabela 4 e Figura 3) foram obtidos os melhores resultados, com reduções de $87 \%$ na DBO, $54 \%$ na DQO, $87 \%$ em óleos e graxas, e $99 \%$ em nitrogênio amoniacal. Apesar disso, essa opção não é indicada para um fluxograma de tratamento porque a fração sólido-líquido (400g de blendaditivado/L de chorume) ultrapassa limite operacional ótimo do filtro-prensa (200g sólido/1L fração líquida). Além disso, os consumos do produto depurante e de energia seriam duplicados, restando ainda os problemas relativos a uma quantidade muito maior de LMIX.

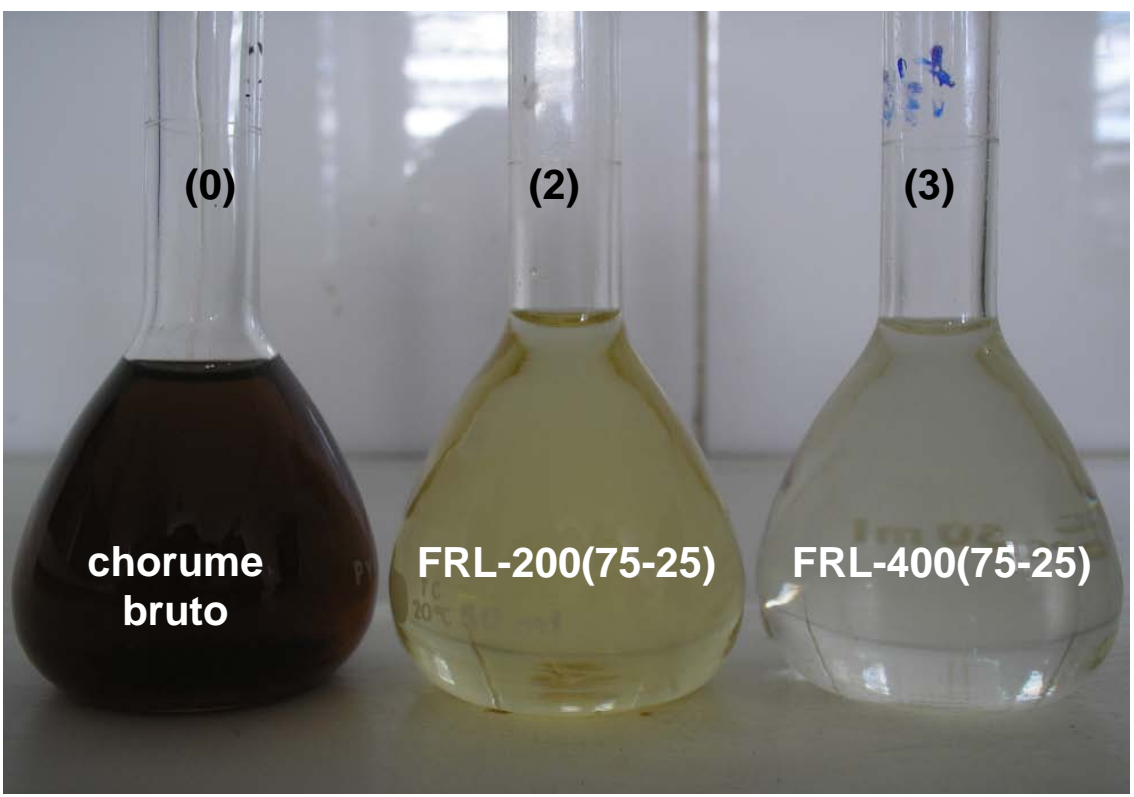

Figura 3 - Redução da cor e turbidez no processo GAD

O maior entrave do processo GAD é o pH das FRL's. Os permeados exibem alcalinidades elevadas $(\mathrm{pH}>11)$ em função de sais dissolvidos, necessitando de correção para que o efluente possa ser descartado em um corpo hídrico, de acordo com os padrões CONAMA 357 (2005). Contudo, esse é um fator pouco preocupante, porque existem técnicas, inclusive de baixos custos, que asseguram a solução desse problema, sendo a diluição um método alternativo simples e bastante eficaz. Seguramente, o mais importante é saber que esse processo representa 33,3\% da fração líquida bruta gerada (chorume bruto), o qual deixaria de ser descartado no corpo receptor, ou mesmo ser lançado de volta no aterro (recirculação). 


\section{CONCLUSÕES}

1) O desempenho do blendcaulínico aditivado mostrou-se eficiente na função de provocar a degradação de parte substancial da MO recalcitrante, passante no tratamento via cepas bacterianas na ETP da Muribeca;

2)A condição LMIX-200(75-25) teve uma boa eficácia, atuando diretamente no percolado bruto (input), sendo indicada para um pré-tratamento e/ou tratamento alternativo;

3) No tocante aos parâmetros analisados na georremediação, destaca-se o blendcaulínico aditivado pela performance de depuração (processo GAD). Além da excelente remoção de MP perigosos (faixa de 67-95\%), DBO (87\%), DQO (54\%), óleos e graxas (70,4\%), amônia (94,3\%), redução volumétrica do percolado bruto $(33,3 \%)$ e remoção da fração supracoloidal do chorume bruto ( $>95 \%$ ), a aplicação do aditivo removeu substancialmente a cor e turbidez (>90\%), o que favorece o tratamento complementar (polimento) do percolado pelos processos biológicos convencionais existentes;

4) Sendo o permeado do processo GAD muito alcalino $(\mathrm{pH}=10-12)$ precisa de correção para permitir que este efluente (FRL) possa ser descartado no corpo hídrico, de acordo com os padrões de lançamento exigidos pela legislação ambiental. Considerando este fato uma limitação do processo, pode-se afirmar com segurança que a alcalinidade elevada tem solução, uma vez que existem técnicas convencionais que fazem esse tipo de trabalho, sendo a diluição um método alternativo. Nesse caso, adicionalmente, a diluição melhoraria ainda mais a qualidade do efluente, reduzindo a concentração de DBO, DQO e metais pesados remanescentes;

5)De acordo com os resultados, poder-se-ia considerar que sua utilização seria factível para produção de farinha de clínquer para cimento, e/ou como matéria-prima para tijolos prensados;

6) A viabilidade técnica do processo GAD está explícita diretamente no tempo de processamento e qualidade do efluente tratado, merecendo destaque a drástica remoção de MP perigosos, que normalmente contribuem com o passivo ambiental acumulativo nas técnicas tradicionais. Além dessa grande vantagem, o sistema permite um controle operacional de tratamento do efluente, independentemente das condições climáticas, cepas bacterianas e da presença de substâncias recalcitrantes presentes no percolado.

\section{REFERÊNCIAS BIBLIOGRÁFICAS}

1. ALVES, I. R. de F. S.; SILVA, F. M. S.; LINS, C. M. M.; LINS, E. A. M. e SOBRINHO, M. A. da M. (2006). Tratamento de Chorume por Coagulação/Floculação. In: VIII Simpósio Ítalo-Brasileiro de Engenharia Sanitária e Ambiental. Fortaleza: ABES, setembro.

2. APHA (2005). Standard Methods for the Examination of Water and Wastewater.Ameriacan Public Health Association, $21^{\text {th }}$ Edition, Washington DC.

3. BELTRÃO, K. G. Q. DE B. (2006). Sistema de Barreira Bioquímica como Alternativa para Tratamento de Percolado. Recife: Geotecnia/Ufpe. Tese de Doutorado em Engenharia Civil. 
4. CINCOTTO, M. A. (1977). Estudo da Composição Química da Cal Hidratada. São Paulo: EPUSP. Dissertação de Mestrado.

5. JUCÁ, J. F. T.; MARIANO, M. O. H e MELO, V. L. A. de (1999). Recalques e Decomposição da Matéria Orgânica em Aterros de Resíduos Sólidos na Região Metropolitana do Recife. In: Congresso Brasileiro de Engenharia Sanitária e Ambiental.

6. LINS, E. A. M. (2003). A Utilização da Capacidade de Campo na Estimativa do Percolado Gerado no Aterro da Muribeca.Recife: Geotecnia/Ufpe. Dissertação de Mestrado em Engenharia Civil, 142p.

7. LINS, E. A. M.; LINS, C. M. MOTA; FIRMO, A. L. B.; ALVES, M. C. M. E JUCÁ, J. F. T. (2006). Sistema de Tratamento de Chorume Proposto Para o Aterro Sanitário da Muribeca. In: VIII Simpósio Ítalo-Brasileiro de Engenharia Sanitária e Ambiental. Fortaleza: ABES, Setembro, 6p.

8. PEZENTE, J. H. Cal nas Argamassas.<http://www.escolher-e-construir.eng.br>.. Acesso em: 20 de maio de 2007.

9. PICCHI, F. A.; CinCOTTO, M. A.; OLIVEIRA, A. A. e GUiMARÃES, J. E. P. (1988). Tijolos Solo-Cal uma Opção para Construção Civil. Rev. Tecnologia, setembro, p. 09-13.

10. SECRETARIA DE SERVIÇOS PÚBLICOS/EMLURB (2007). $<$ http://www.recife.pe.gov.br/pr/servicospublicos/emlurb/aterrosanitario.php $>A$ cesso em: 25 de março 2007. 